\title{
Visual reaction time of drivers versus healthy adults: a comparative study Mrigendra Amatya' ${ }^{1}$, Samjhana Thapa ${ }^{2}$, Roshan Kasti ${ }^{2}$, Ojashwi Nepal ${ }^{3}$
}

\section{Author(s) info:}

${ }^{1}$ Department of Physiology, Nepal Medical College, Kathmandu, Nepal

${ }^{2}$ Kathmandu University School of Medical Sciences, Dhulikhel, Kavre, Nepal

${ }^{3}$ Department of Physiology, Kathmandu University School of Medical Sciences, Dhulikhel, Kavre, Nepal

\section{Correspondence:}

Dr. Mrigendra Amatya, $M B B S, M D$ Department of Physiology, Nepal Medical College, Gokarneswor-8, Kathmandu.

\section{Email:}

amatyam01@gmail.com

\begin{abstract}
Introduction: Driving is a highly demanding profession requiring heightened alertness while remaining in an ergonomically constrained position and also associated with exposure to vehicular pollution and whole body vibration. We explored whether drivers' reaction time is different to student group who also remain in sitting position for long hours but not exposed to other factors.
\end{abstract}

Materials and methods: Drivers with at least one year of occupational history and under/post-graduate students were randomly selected. Their reaction time in seconds (RT) was measured by the ruler drop method (RDM) and compared with independent $t$ test. Right vs left hand RTs were compared within groups by paired $t$ test.

Results: Thirty students (21.8 \pm 2.25 years) and 37 drivers (33.73 \pm 9.77 years) participated in the study. The drivers had RT of $2.03 \pm 0.2 \mathrm{~s}$ on both the hands; students' RT were $2.01 \pm 0.16 \mathrm{~s}$ on right and $2.02 \pm 0.17 \mathrm{~s}$ on left hands. For both hands, the differences were not significant between drivers and students $(\mathrm{p}>0.5)$. Right and left RT were also comparable for both groups ( $\mathrm{p}>0.5)$.

Conclusions: Bus drivers with at least one year occupational exposure have reaction times ruler drop stimulus not significantly different from controls (students).

Keywords: drivers, occupation, reaction time, ruler drop test, students

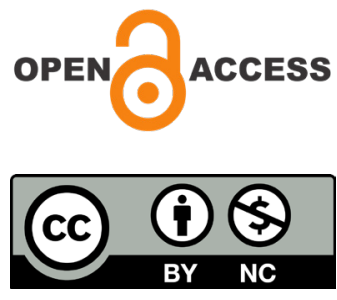

(C) JPSN 


\section{INTRODUCTION}

Reaction time (RT) is defined as interval of time between presentation of stimulus and appearance of appropriate voluntary response in a person. [1] RT can be measured by different methods. It has physiological significance as a simple noninvasive test for peripheral as well as central neural structures.[2]

RT is affected by several factors such as stimulus type, stimulus intensity, state of arousal, age, gender, left or right side, practice, fatigue, distration, warning of impending stimuli, alcohol, exercise, illness, etc. [3,4]

Especially, RT has been used to assess psychomotor performance, cognitive function, and peripheral nerve functions in conditions such as diabetes mellitus, head injury, postoperatively, and hypoxic challenges.[5-8]

Whether RT is affected in anyway by the occupation of an individual has not been reported. However, sports professionals such as basketball and table tennis players have faster RT compared to nonplaying controls. $[9,10]$

Driving is a highly demanding profession from a cognitive perspective (attention, information perception and processing, decision making). A driver is exposed to whole body vibration, diesel exhaust and noise while all the while staying within the confines of the driver's seat.[11,12] Many morbidities, especially disorders of the locomotor system and peripheral nerves, are more common in the drivers as compared to the general population. $[13,14]$ As a result of these factors, the RT in drivers may be affected but has not been reported so far.

\section{MATERIALS AND METHODS}

A quantitative, cross-sectional study was designed which was approved by the Institutional Review Committee of the Kathmandu University School of Medical Sciences (KUSoMS), Dhulikhel, Kavre, Nepal. The study was conducted in the period of $15^{\text {th }}$ March to $14^{\text {th }}$ August, 1999. Participants were randomly selected from a pool of drivers and students. Informed written consent was obtained from all participants.

The student group comprised of undergraduate and postgraduate students of the KUSoMS. The driver group consisted of passenger bus drivers (in the Kathmandu-Dhulikhel route), who are in the occupation for at least one year. All the participants were apparantly healthy individuals, who were free from any chronic health conditions and not taking any medications. Participants having recent injuries and open wounds to the hands were excluded. General information and anthropometric measurements were taken.

For recording the reaction time (RT) by the ruler drop method (RDM), the participant was seated in a chair and rested his elbow over the table at $90^{\circ}$ flexion with the forearm in mid-pronated position. His thumb and index fingers were made to open at about $25 \mathrm{~mm}$ distance, with the help of a spacer. The examiner held a metal ruler by its upper end vertically such that its lower end was levelled between teh thumb and index fingers. The participant was instructed to focus on the lower end of the ruler and grab it as soon as the examiner dropped the ruler without any cue. Prior to recording, the test was demonstrated to the participant as well as allowed two trials.

The distance travelled by the ruler was recorded and converted to time $(\mathrm{t})$ as follows:

$$
\mathrm{t}=\sqrt{\mathrm{d} / \mathrm{g}}
$$

where,

$$
\begin{aligned}
& \mathrm{t}=\text { reaction time (milliseconds, } \mathrm{ms} \text { ), } \\
& \mathrm{d}=\text { distance travelled by the ruler (millimeters, } \\
& \mathrm{mm} \text { ), and }
\end{aligned}
$$$$
\mathrm{g}=\text { gravitational constant }\left(9.81 \mathrm{~m} / \mathrm{s}^{2}\right) .
$$

Finally, the participant performed three attempts and the RT was determined as the mean (average) of the three values.

The drivers' mean RT of either hand were compared with the controls by independent $t$ test (SPSS version 16.0). Also, the right and left hand RTs were compared within group by paired $t$ test to see effect of hand dominance. A p value of 0.05 or less was considered statistically significant.

\section{RESULTS}

The study was completed in 37 drivers (all males) and 30 students (23 males, 7 females). Students were significantly younger than the drivers and also had less age variation within group. In other general characteristics, the two groups had no significant 
Table 1: Comparison of general characteristics of study participants (independent $t$ test)

\begin{tabular}{|l|c|c|c|}
\hline \multicolumn{1}{|c|}{ Parameters } & Students $(\mathbf{n}=30)$ & Drivers $(\mathbf{n}=37)$ & P value \\
\hline Age $($ years $)$ & $21.8 \pm 2.25$ & $33.73 \pm 9.77$ & 0.000 \\
\hline Height $(\mathrm{cms})$ & $164.6 \pm 11.54$ & $165.51 \pm 5.89$ & 0.676 \\
\hline Weight $(\mathrm{Kgs})$ & $63.32 \pm 11.46$ & $66.76 \pm 6.35$ & 0.125 \\
\hline BMI $\left(\mathrm{Kg} / \mathrm{m}^{2}\right)$ & $23.43 \pm 4.18$ & $24.45 \pm 2.76$ & 0.236 \\
\hline
\end{tabular}

Table 2: Comparison of reaction time of drivers and students (independent $t$ test)

\begin{tabular}{|l|c|c|c|}
\hline \multicolumn{1}{|c|}{ Reaction time (sec) } & Students & Drivers & P value \\
\hline Right hand & $2.01 \pm 0.16$ & $2.03 \pm 0.2$ & 0.555 \\
\hline Left hand & $2.02 \pm 0.17$ & $2.03 \pm 0.22$ & 0.903 \\
\hline
\end{tabular}

Table 3: Right-left comparison of reaction time (independent $t$ test)

\begin{tabular}{|l|c|c|c|}
\hline \multirow{2}{*}{ Groups } & \multicolumn{2}{|c|}{ Reaction time (sec) } & \multirow{2}{*}{ P value } \\
\cline { 2 - 3 } & Right & Left & \\
\hline Students (30) & $2.01 \pm 0.16$ & $2.02 \pm 0.17$ & 0.563 \\
\hline Drivers (37) & $2.03 \pm 0.2$ & $2.03 \pm 0.22$ & 0.936 \\
\hline
\end{tabular}

differences (Table 1). On the average, the drivers worked for about 5 hours in a day; the median years in the driving occupation was 8 years.

The RT calculated from the RDM were compared between the groups (Table 2). In either hand, the RT was not significantly different between the groups.

Finally, the right and left hand RTs were compared (Table 3). In both groups, the RTs were strongly corrrelated and comparable to the other side. In the drivers, the two hands' RTs were almost identical. In the students, RT was marginally faster in the right hand.

\section{DISCUSSION}

Simple RT measures how quickly a person performs a uniform response to a specific stimulus and ruler drop method is one simple method to estimate the simple RT. It involves a specific motor response to a visual stimulus (a dropping ruler).[15] RT is considered a reliable indicator of processing of sensory stimulus by the central nervous system and its execution in the form of a motor responsee and has been used frequently in assessing peripheral nerve function such as in diabetes mellitus.[16] In this study, we compared the RT (RDM) of occupational drivers with a student control group 
to explore if these factors affected the drivers' RT. Our study found no significant differences between the drivers and controls in either hands, dominant or non-dominant (Table 2).

Drivers are an occupational group that is exposed to prolonged whole body vibrations, environmental and vehicular pollutions, and ergonomic constraints. As a result, occupational drivers are prone to develop many morbidities, especially disorders of the locomotor/musculoskeletal system and peripheral nerves.[13,14,17] Most studies have assessed the occcupational risks of the driver population by using objective tools such as preset questionnaires, self-reported symptomatology, and interviews. An objective evidence of drivers suffering ulnar nerve entrapment at the elbow was reported by Afsar et al (2014) as increased latency and slower conduction of the ulnar nerve in drivers habitually leaning their elbow on the taxi windows. [18] In another study, Kanagamuthu et al (2018) found significant nerve conduction slowing and decreased pain threshold in drivers compared to the controls.[19] In the Nepalese drivers, we had reported that median and ulnar nerve afflictions are detectable in taxi/microbus drivers and microbus helpers (conductors) with at least six months' occupational duration.[20]

Electrophysiological tests (that is, nerve conduction studies) is highly regarded for the diagnostic evaluation of a variety of peripheral nerve conditions and even detect pre-clinical nerve conditions.[21,22] Obviously, the nerve conduction study (NCS) is a time and effort consuming procedure, which is not practical in field settings. On the other hand, reaction time measurement by simple means like RDM is both quick and easy to administer. The special characteristics of RT is the involvement of cognitive and voluntary component to motor response which is not seen in NCS.

$\mathrm{RT}$ is found to be faster with exercise, practice, and anticipation of stimulus. $[3,9,10]$ Driver occupation probably prepares a person to respond fast to stimuli, especially related to traffic navigation and road-related incidents.[23] Although, many other factors may have their influences. As stated earlier, reports on comparative studies of drivers and general population are lacking. This study did not find significant differences between drivers and students in a selected sample. The findings of this study are admittedly inconclusive.
Small sample size, unmatched control group, and lack of standard reference are the limitations of this study. In future studies, the findings can be verified with use of other tests of RT such as brake-reaction time, stroop test, and even nerve conduction studies.

\section{CONCLUSION}

The reaction time by ruler drop method was not significantly different in the Dhulikhel-Kathmandu route drivers with at least one year of occupational history and students of a medical college. Also, there were no differences in right and left hand reaction times in either group. Our findings do not support the assumption that reaction time is affected by the driver occupation.

\section{ACKNOWLEDGEMENTS}

We gratefully acknowledge the University Grants Commission, Sanothimi, Bhaktapur, Nepal for providing the support to conduct this study.

\section{CONFLICT OF INTEREST}

None

\section{REFERENCES}

1. Ilamkar KR. Analysis of human information processing in performance and cognition. Int J Res Heal Sci 2014; 2(1): 36-40.

2. Mohan M, Thombre DP, Das AK, Subramanian N, Chandrasekar S. Reaction time in clinical diabetes mellitus. Indian J Physiol Pharmacol 1984; 28(4): 311-4.

3. Geis CE, McCarthy K, Alexander B, Blake D, Tosti M, Schnabl J. Factors affecting reaction time. Sci J Rev 2010; 1-23.

4. Der G, Deary IJ. Age and sex differences in reaction time in adulthood: Results from the United Kingdom health and lifestyle survey. Psychol Aging 2006; 21(1): 62-73.

5. Scott W, Whitwam J, Wilkinson $R$. Choice reaction time - a method of measuring postoperative psychomotor performance decreements. Anaesthesia 1983; 38: 1162-8.

6. Stuss DT, Hugenholtz H, Pivik J, Richard T. Reaction time after head injury: fatigue, divided and focused attention , and consistency of performance. J Neurol Neurosurg Psychiatry 1989; 52: 742-8.

7. Nyhus E, Barceló F. Brain and Cognition The Wisconsin Card Sorting Test and the cognitive assessment of prefrontal executive functions: A critical update. Brain 
Cogn 2009; 71(3): 437-51.

8. Davranche K, Casini L, Arnal PJ, Rupp T, PerreyS, Verges S. Cognitive functions and cerebral oxygenation changes during acute and prolonged hypoxic exposure. Physiol Behav 2016; 164: 189-97.

9. Bhabhor MK, Vidja K, Bhanderi P, Dodhia S, Kathrotia $R$, Joshi $V$, et al. A comparative study of visual reaction time in basketball players and healthy controls. Indian $J$ Physiol Pharmacol 2013; 57(4): 439-42.

10. Ghuntla T, Mehta H, Gokhale P, Shah C. A comparative study of visual reaction time in table tennis players and healthy controls. Natl J Integr Res Med 2012; 3(1): 49-51.

11. Hanzlikova I. Professional drivers: the sources of occupational stress 2005. Available from: http://www. ectri.org/YRS05/Papiers/Session-4/hanzlikova.pdf

12. Whitelegg J. Health of professional drivers. A Report for Transport and General Workers Union. Lancaster; 1995. Available from: https://www.eco-logica.co.uk/pdf/ HealthProDrivers.pdf

13. Szeto GPY, Lam P. Work-related musculoskeletal disorders in urban bus drivers of Hong Kong. J Occup Rehabil 2007; 17: 181-98.

14. Rehn B, Nilsson T, Jarvholm B. Neuromusculoskeletal disorders in the neck and upper extremities among drivers of all-terrain vehicles - a case series. BMC MusculoskeletDisord 2004; 5(1): 1-7.

15. Eckner JT, Richardson JK, Kim H, Ashton-miller JA. A novel clinical test of recognition reactin time in healthy adults. Psychol Assess 2012; 24(1): 249-54.

16. Sidhu J, Mittu S, Sidhu H. Visual reaction time changes in type 2 diabetics and non-diabetics. Arch Appl Sci Res 2015; 7: 59-61.

17. Chen J-C, Chang $W-R$, Chang $W$, Christiani D. Occupational factors associated with low back pain in urban taxi drivers. Occup Med (Chic Ill) 2005; 55: 53540.

18. Afşar Sİ, Çetin N, Ayaş Ş, Mumcu GA, Karataş M. Ulnar nerve conduction abnormalities in Turkish taxi drivers. Arch Rheumatol 2014; 29(2): 110-7.

19. Kanagamuthu R, Mohanraj S, Sengottaiyan A. Analysis of motor nerve conduction and pain threshold in professional drivers. Ann Int Med Den Res 2018; 4(5): PH04-07.

20. Amatya $M$, Khanal B. Median and ulnar nerve functions in taxi/microbus drivers and helpers in Kathmandu. J Kathmandu Med Coll 2019; 8(3): 151-5.

21. Abdelazeem M, El-Zohiery A, Elhussieny M. Subclinical peripheral nerve affection in hypothyroidism. Egypt $J$ Hosp Med 2017; 67(2): 553-63.

22. Lee DH, Claussen GC, Oh S. Clinical nerve conduction and needle electromyography studies. J Am Acad Orthop Surg 2004; 12: 276-87.

23. Summala $H$. Brake reaction times and driver behavior analysis. Transp Hum Factors 2000; 2(3): 217-26. 